\title{
The Influential Factors in the Awareness, Attitude, and Practice of Mothers with Toddlers in Preventing Domestic Accidents
}

\author{
Narges Kalvandi ${ }^{1}$, Amir Hossein Gholami ${ }^{2}$, Danesh Kamangar ${ }^{3}$, Roya Amini ${ }^{4}$ \\ Faezeh Biglari ${ }^{5}$
}

\begin{abstract}
Background \& Aims: Accidents are a chain of events that lead to damage and detectable disease. Although some consider home to be the safest place, about a third of incidents occur at home. One of the high-risk groups in domestic accidents is toddlers. Physiological patterns associated with the developmental stages of toddlers make this group susceptible to such events, so that accidents are the main cause of death in the first five years of children's lives worldwide. Health education programs can empower parents to prevent domestic accidents. On the other hand, the effectiveness of health education programs is mostly dependent on having accurate information about mothers' awareness, attitude, and practice. Considering that more evidence is needed to take necessary measures to implement related interventions, this study aimed to determine the factors related to awareness, attitude, and practice of mothers of toddlers in preventing domestic accidents.

Materials \& Methods: This was a descriptive correlational study conducted on 280 mothers with toddlers referred to community health centers from April to September 2019. In this study, multistage cluster sampling method was used to collect data. Each area of the north and south regions of Hamadan city was considered as a cluster and two comprehensive health centers were selected from each cluster through simple random method and among the selected comprehensive health centers, mothers were selected through convenience sampling method and based on inclusion criteria. Inclusion criteria were living in Hamadan city, having at least one toddler, not having a toddler with incurable diseases, and not being pregnant. Also, exclusion criteria included reluctance to continue participation in the study despite the initial agreement. Data collection tools were demographic questionnaires, history of injury, and a researcher-made questionnaire based on awareness, attitude, and practice in preventing domestic accidents that were completed by the samples. In order to determine the validity of the questionnaire, qualitative content validity was used, and test-retest was used to check the reliability of the instruments. After writing the proposal and approving the plan, the researcher referred to the comprehensive health centers of Hamadan city and identified the mothers of toddlers with inclusion criteria and invited them by telephone or with the help of the staff to participate in the project. All mothers were given the necessary explanations about the objectives, procedure, and duration of the study (6 months), and written informed consent was obtained from them. At the beginning of the study, the subjects were given the data collection tools and the self-assertion questionnaires were completed. In order to provide a calm environment for answering questions, mothers (as representatives of parents) were asked to leave their children to their companions before receiving clinic services (vaccination, and growth monitoring) and answer questions in the educational class of the relevant centers. After completing the questionnaires, data were analyzed using Kolmogorov-Smirnov tests to ensure normal distribution, Kruskal-Wallis to determine the relationship between
\end{abstract}

\footnotetext{
1. Department of Nursing, Community Health Nursing, Asadabad Faculty of Medical Sciences, Asadabad, Iran.

2. Department of Community Health Nursing, School of Nursing and Midwifery, Chronic Diseases (Home Care) Research Center, Hamadan University of Medical Sciences, Hamadan, Iran

3. Student Research Committee, Hamadan University of Medical Sciences, Hamadan, Iran

${ }^{4}$. Department of Community Health Nursing, School of Nursing and Midwifery, Chronic diseases (Home Care) Research Center, Hamadan University of Medical Sciences, Hamadan, Iran. (Corresponding Author) Tel:08132520182 Email: aminiRoy@umsha.ac.ir

5. Chronic Diseases (Homecare) Research Center, Dept. of Community Health Nursing, School of Nursing and Midwifery, Hamadan University of Medical Sciences, Hamadan, Iran
} 
qualitative demographic variables and awareness, attitude towards behavior and practice, and Spearman correlation test to determine the relationship between quantitative demographic variables with awareness, attitude towards behavior and practice in SPSS 16 software.

Results: According to the results, $(44.6 \%)$ of the mothers of toddlers had a university education and $(72.8 \%)$ of the mothers were housewives. Also, $(58.3 \%)$ of toddlers were girls and (46.7\%) of parents kept their children in kindergarten. Mean scores of awareness with a value of $18.1 \pm 1.5$ was the highest point obtained by mothers (good), mean scores of mothers' attitudes with a value of $18.8 \pm 4.6$ regarding the adoption of preventive behaviors were regarded as weak, and the mean score of practice with a value of $24.3 \pm 10.1$ was regarded as good. Also, a positive significant relationship was observed between the age of the toddler and the level of awareness, between the family dimension and the number of children, and between the age of the toddler with the mother's attitude towards behavior, between maternal education and awareness and practice, between father's education with awareness, attitude and practice, between father's employment status with awareness and attitude, between mother's employment status with awareness, and between childcare status with attitude (P $<0.05)$. Among the total number of people surveyed, 15 toddlers were injured in the accident. Burning, poisoning, asphyxia, and drowning were respectively the accidents occurring in the children with a history of injury. (72\%) of these cases had resulted in temporary disability and 13 victims were girls. All reported cases had occurred in the age group of one to one and half-year-old toddlers.

Conclusion: Considering the poor average scores in attitude and practice of mothers and also considering the important role of education in promoting preventive behaviors of accidents, it is necessary to educate mothers more in order to improve their awareness, attitude, and practice regarding the prevention of children's accidents. Also, the findings of this study and similar researches in this field can be a guideline for planners and authorities to use the present findings to perform interventions to improve the awareness, attitude, and practice of mothers about the prevention of domestic accidents in toddlers.

Keywords: Practice, Domestic Accidents, Children, Toddler

\section{Conflict of Interest: No}

How to Cite: Kalvandi N, Gholami AH, Kamangar D, Amini R, Biglari F. The Influential Factors in the Awareness, Attitude, and Practice of Mothers with Toddlers in Preventing Domestic Accidents. Iran Journal of Nursing. 2021; 34(130):91-103.

Received: 17 March 2021

Accepted: 21 Jun 2021 


\title{
بررسى عوامل مرتبط با آكاهى، نكرش و عملكرد مادران نويا در يِشكيرى از حوادث خانكى
}

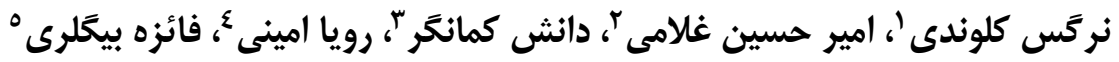

جִكنه

مقدمه و هدف: حوادث خانكى اولين علت مرگ و معلوليت در كودكان است. اثر بخشى برنامهاى آموزشى بهداشت در زمينه يِشخيرى از حوادث

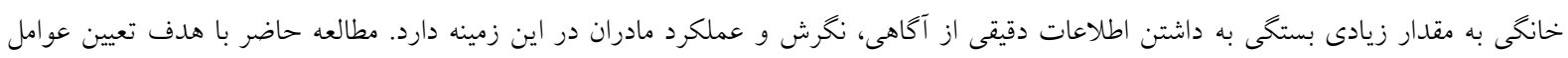

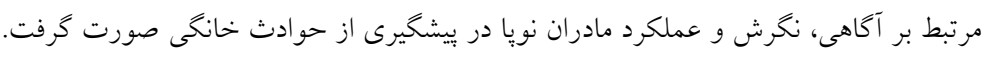

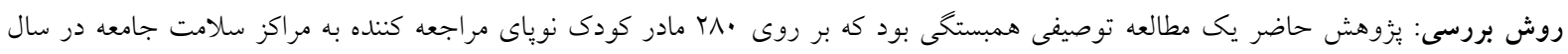

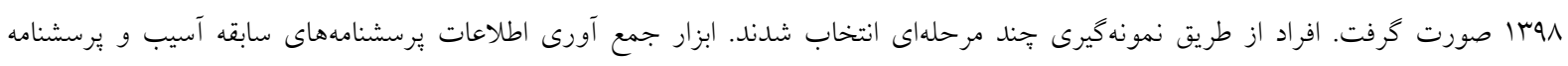

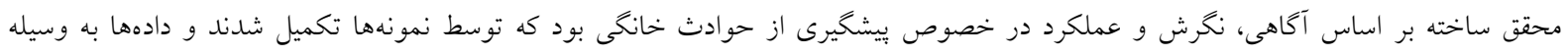

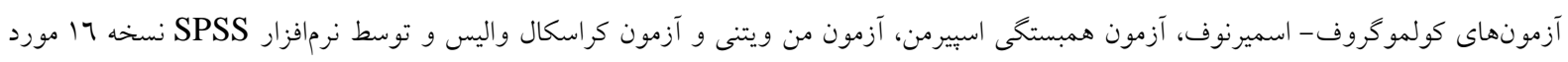
تحليل قرار گرفتند.

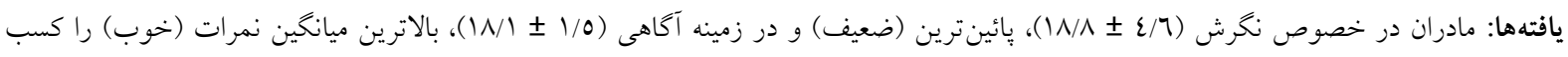

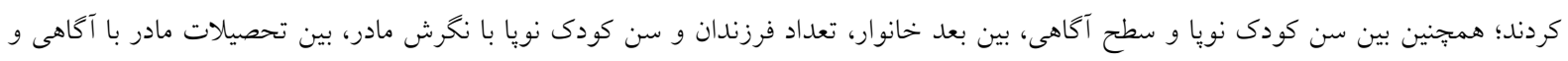

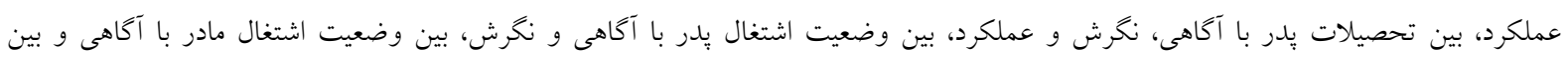

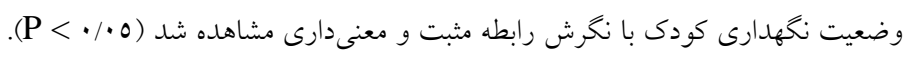

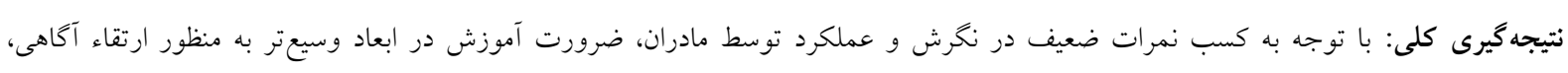
نخرش و عملكرد مادران در خصوص بيشخيرى از سوانح و حوادث كودكان احساس مى كردد.

كليد وازهها: عملكرد، حوادث خانحى، كود كان، نويا

تعارض منافع: وجود ندارد.

تاريخ دريافت: 99/I T/TV

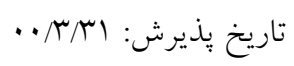

' ' ' كروه يرستارى يرستارى، دانشكده علوم يزشكى اسدآباد، اسدآباد، ايران

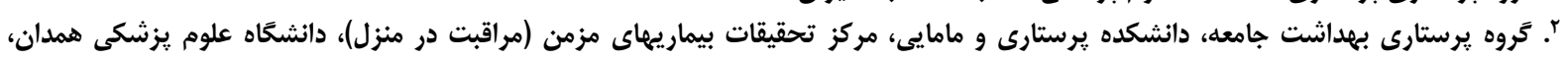
همدان، ايران

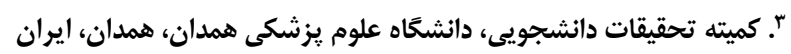

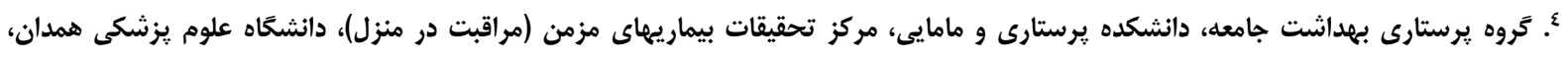

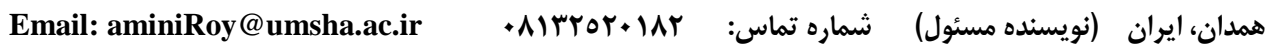

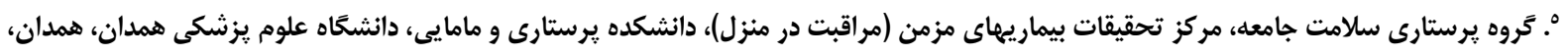


نظر به اين كه براى اتخاذ تدابير لازم در جهت اجراى

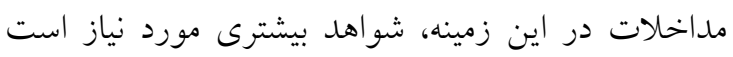

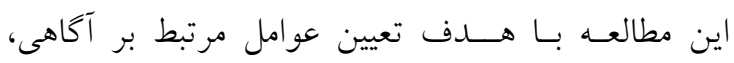

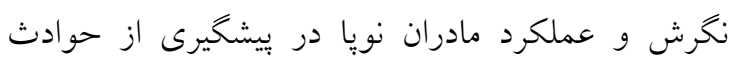
خانكى انجام شد.

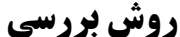

يَزوهش حاضر يك مطالعه توصيفى همبستخى بود كه در بروسي

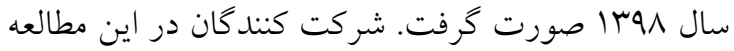
شامل مادران كودكان نوياى مراجعه كننده به جهار مركز

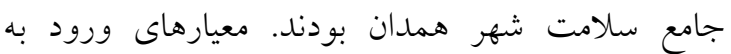
مطالعه شامل سكونت در شهر همدان، داشتن حداقل يك

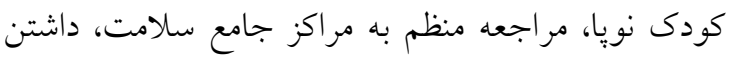

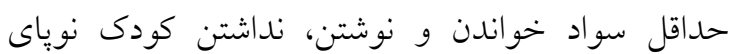
مبتلا به بيمارى صعب العلاج، نبودن مادر در دوران باردارى و تمايل جهت شركت در مطالعه بود(·)، معيار خروج از مطالعه شامل نداشتن تمايل به ادامه مشاركت در مطالعه باوجود موافقت اوليه بود.

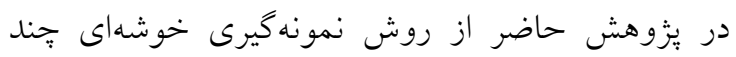

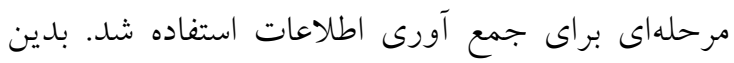

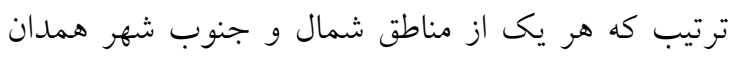

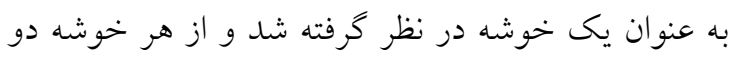
مركز جامع سلامت با روش تصادفى ساده انتخاب شده و از ميان مر اكز جامع سلامت منتخب، مادران به صورت در دستر وارد مطالعه شدند. با استناد به مطالعه رعنايى و

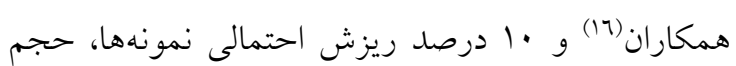

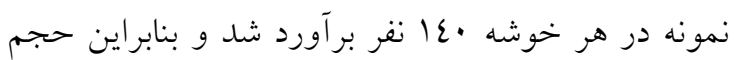

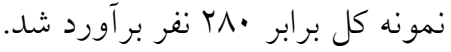

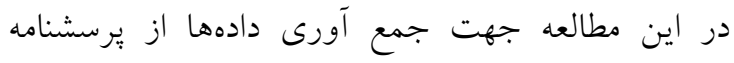
محقق ساخته استفاده شد. يرسشنامه شامل سه قسمت بود كه قسمت اول شامل سؤلات مربوط به اطلاعات دموكرافيك مادر و كودك، قسمت دوم شامل سؤالات

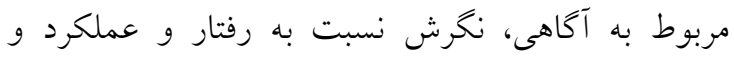

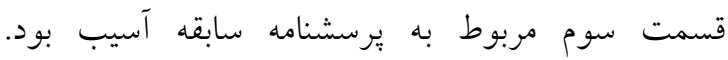

مقدمه

حوادث، زنجيرهاى از وقايع هستند كه منجر به بروز

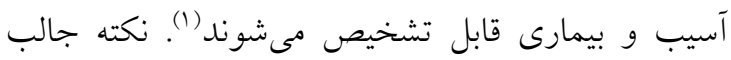

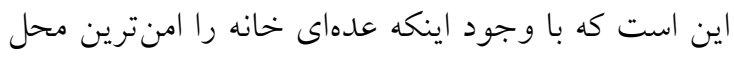

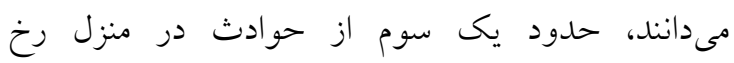

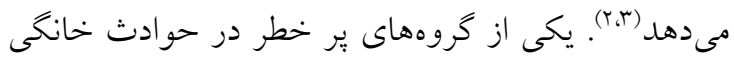

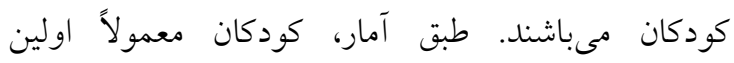
حادثهاى را كه تجربه مى كنند در خانه است (ع). در اين

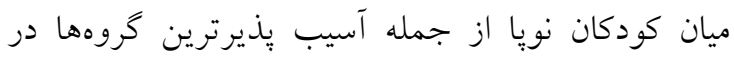

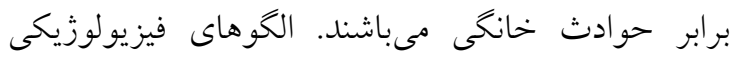

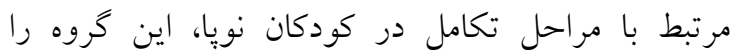
مستعد اين كونه حوادث مى كند (0)؛ به طورى كه حوادث اولين علت اصلى مرگ در ينج سال اول زندگى كودكان

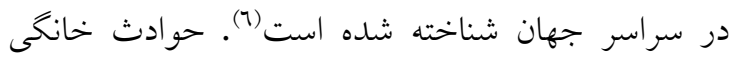
ساليانه جان ... NVO كودى را مى گيرد كه مسئول •ع درصد از كل مرگ كودكان در جهان است (ل، (v).

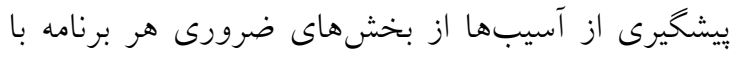

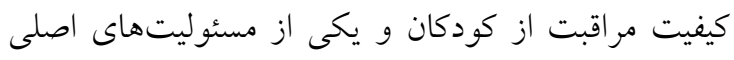

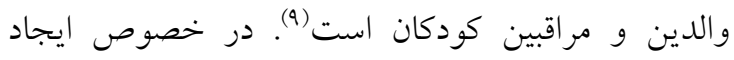
آكَاهى، نخرش و و عملكرد براى كنترل و مهار آسيبهاى

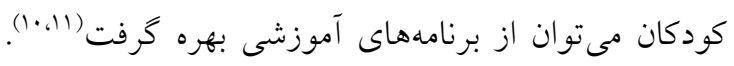

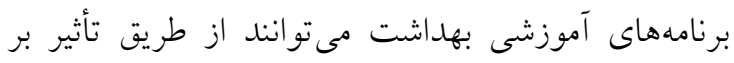

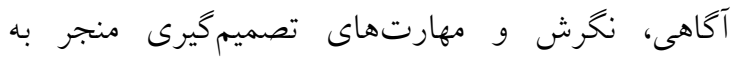

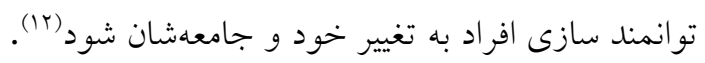
از طرفى اثر بخشى برنامههاى آموزشى بهداشتى به مقدار

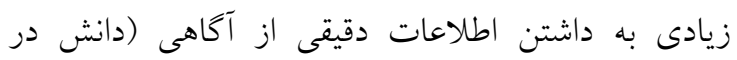

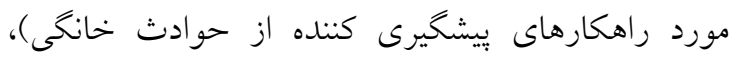

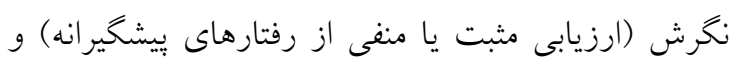

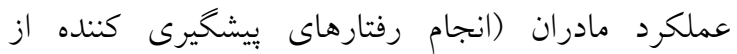
حوادث خانكى) و در نظر گرفتن عوامل مؤثر بر آنها

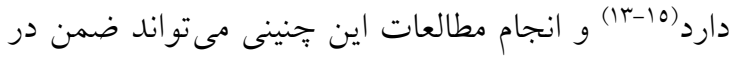
دست قرار دادن اطلاعات دقيق، بسترى را براى برنامه ريزىهاى مناسب و جامع در اين زمينه فراهم نمايد. 
فعاليت كودى و مادر به هنخام وقوع آسيب، نوع ماهيت

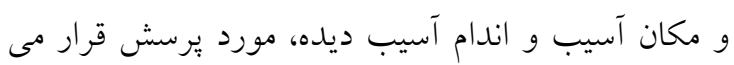
كرفت. به منظور تعيين روايى يرسشنامه از روش اعتبار محتوى

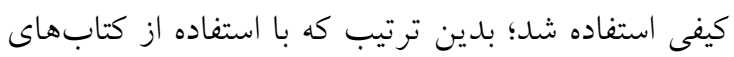

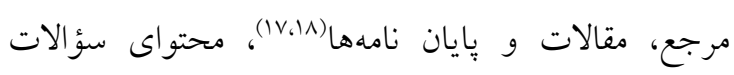

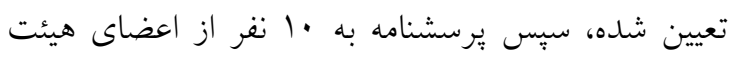

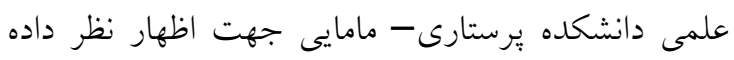
شد و نظرات اصلاحى ايشان در برسشنامه اعمال كرديد.

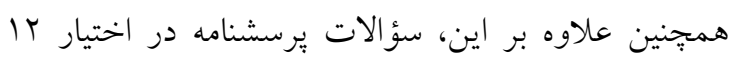

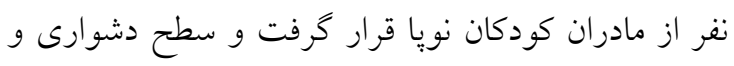
قابل فهم بودن سؤالات توسط آنها مورد بررسى قرار فردار كرفت و اصلاحات مقتضى اعمال گرديد.

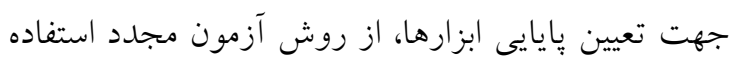

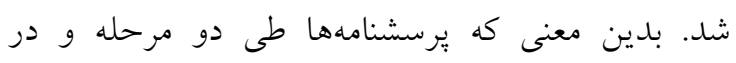

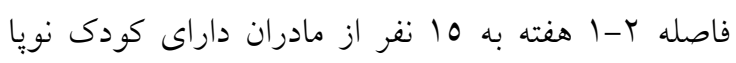

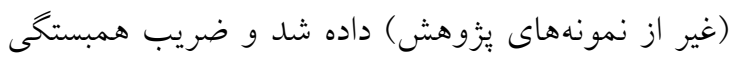

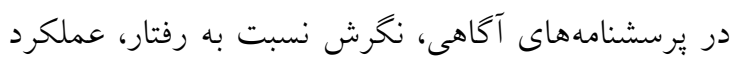

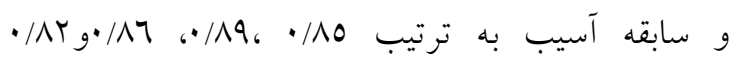
محاسبه شد. همجنين به منظور ارزيابى ساز كارى درونى

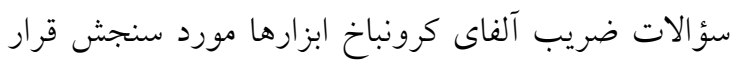

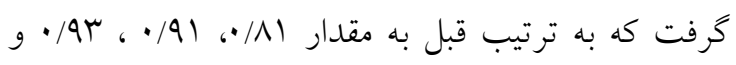

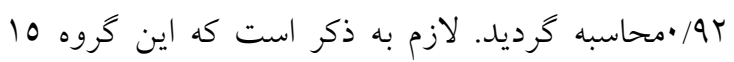
نفره به عنوان شركت كننده در مطالعه در نظر كرفته برديه نشاند. شيوه كار بدين صورت بود كه يس از نخارش يرويوزال و

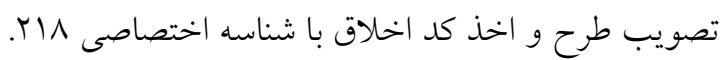
IR.UMSHA.REC.IraV

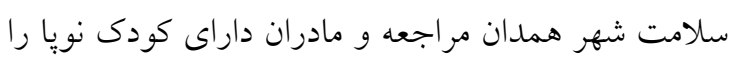
كه مشخصات ورود به مطالعه را داشتند، شناسايى نمود و و مادران

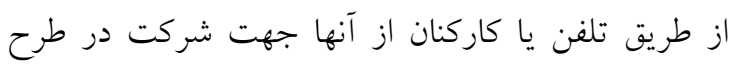

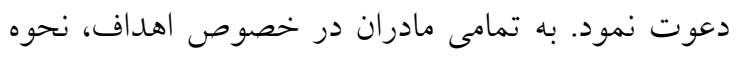

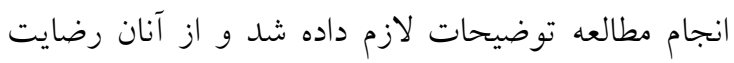

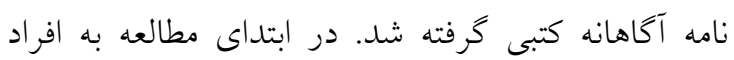

سؤالات مربوط به اطلاعات جمعيت شناختى خود شامل

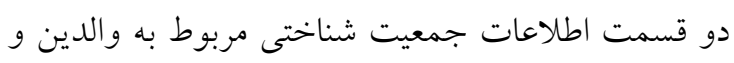
كودى بود؛ بدين صورت كه سؤالات جمعيت شناختى

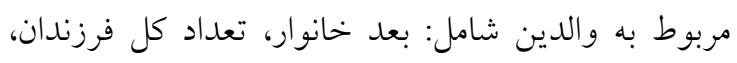

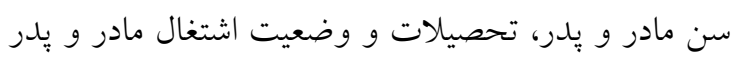

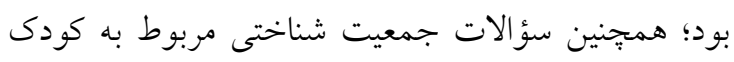

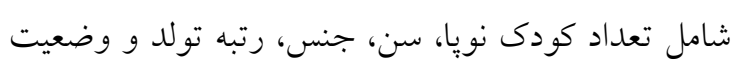
نخهارى كودى در صورت اشتغال مادر در خارج از

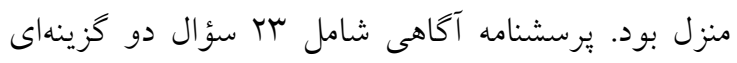
صحيح و غلط بود كه به سنجش و امتيازدهى آكاهى

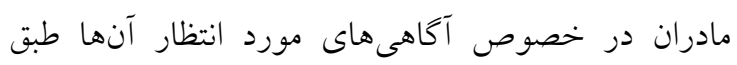

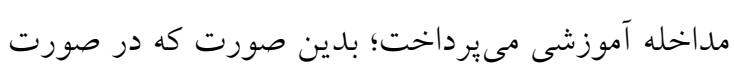

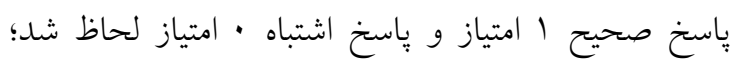

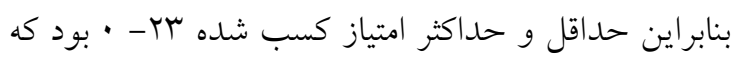
كسب نمره • تا م به صورت آكاهى ضعيف، 9 تا 17 به

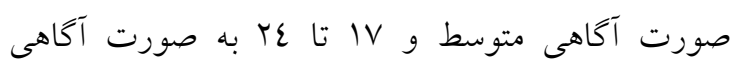

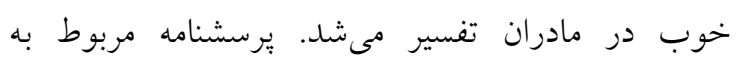

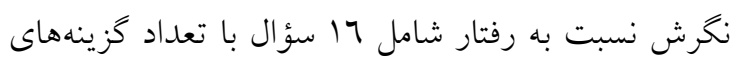

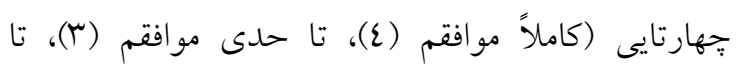

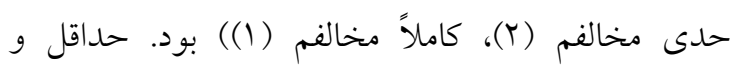
حداكثر نمره كسب شده از اين قسمت به ترتيب عَ-17)

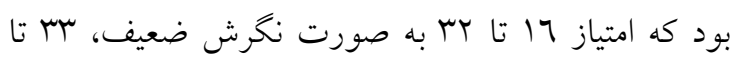

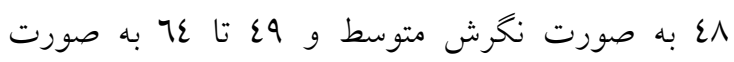

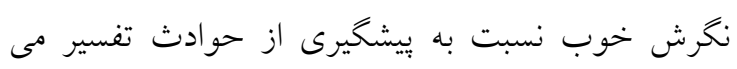

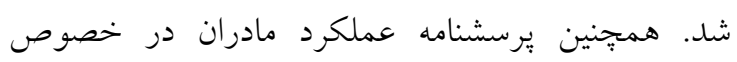

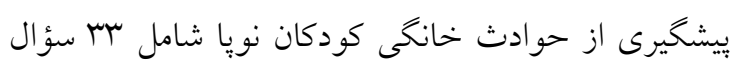

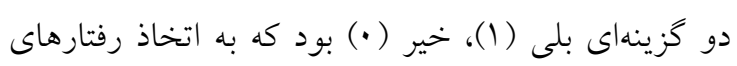

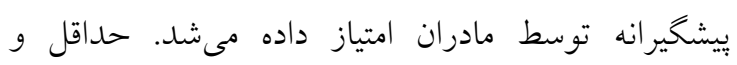

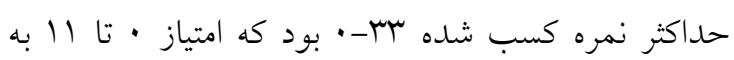

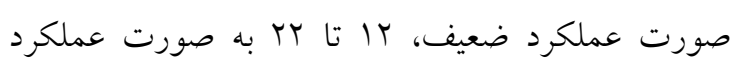

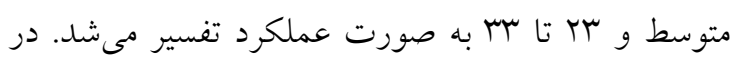

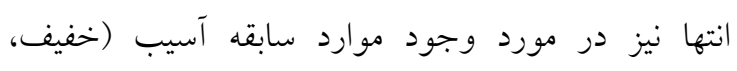

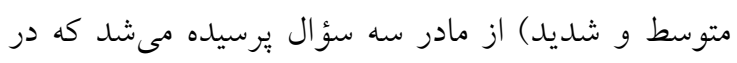

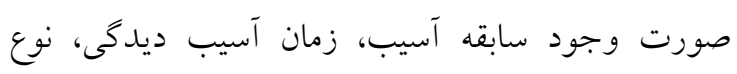




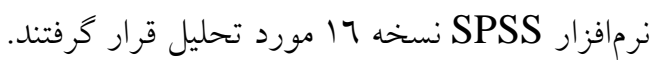

\section{يافتهها}

طبق يافتهاى جدول شماره 1، آعـ درصد از مادران و 9/• •ع درصد از يدران كودكان نويا از تحصيلات

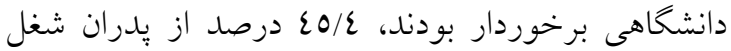
آزاد و VY/A درصد از مادران خانهدار بودند. همجنين

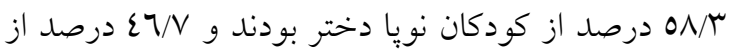
والدين كودى خود را در مهد كودى نخهدارى مى كردند. جزئيات مربوط به اطلاعات دموگرافيك در جدول شماره

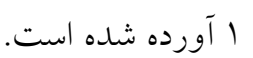

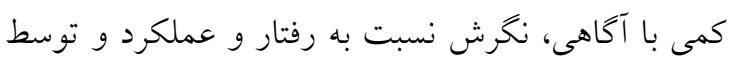

تحت مطالعه ابزار گردآورى دادهها داده شد و برسشنامه ها به روش خود اظهارى تكميل شدند. به منظور تأمين

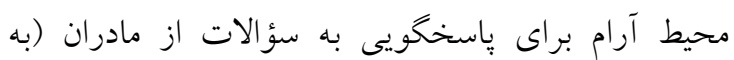

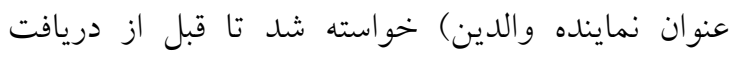
خدمات درمانگاه (واكسيناسيون، و بايش رشدان)، كودكان خود را به همراهان بسيارند و در كلاس آموزشى مراكز مربوطه به سؤالات پِاسخ دهند. يّ از تكميل پرسشنامه

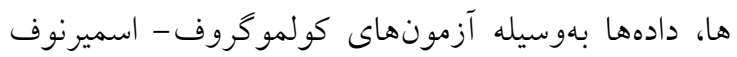
جهت اطمينان از توزيع نرمال، كروسكال واليس جهت

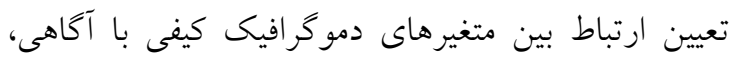

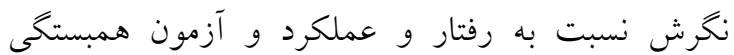
اسبيرمن جهت تعيين ارتباط بين متغيرهاى دموكرافيك جدول شماره (: متغير هاى جمعيت شناختى افراد تحت مطالعه

\begin{tabular}{|c|c|c|c|}
\hline درصد (انحراف معيار) & فراوانى (ميانخين) & سطوح متغير & 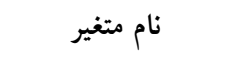 \\
\hline$\cdot / V$ & r & بي بواد & \multirow{5}{*}{ تحصيلات مادر } \\
\hline T/1 & IV & ابتدائى & \\
\hline $\mid \varepsilon / \varepsilon$ & $\varepsilon$. & سيكل س & \\
\hline$r \varepsilon / r$ & 90 & دييلم & \\
\hline$\varepsilon \varepsilon / 7$ & $1 T \varepsilon$ & تحصيلات دانشكاهى & \\
\hline $1 \cdots$ & ५А. & \multicolumn{2}{|c|}{ جمع } \\
\hline$\cdot / \varepsilon$ & 1 & بيىسواد & \multirow{5}{*}{ تحصيلات يدر } \\
\hline$\varepsilon$ & 11 & ابتدائى & \\
\hline$r \cdot / r$ & 07 & سيكل س & \\
\hline$r \varepsilon / \varepsilon$ & 90 & دييلم & \\
\hline$\varepsilon \cdot / 9$ & $11 \mathrm{~V}$ & تحصيلات دانشخاهى & \\
\hline $1 \cdots$ & ५৯. & \multicolumn{2}{|c|}{ جمع } \\
\hline$m-/ 2$ & 91 & كارمند & \multirow{5}{*}{ وضعيت اشتغال بدر } \\
\hline$\varepsilon 0 / \varepsilon$ & Irr & آزاد & \\
\hline $1 \pi / 2$ & ry & كاركر & \\
\hline 1/0 & $\varepsilon$ & دامدار يا كشاورز & \\
\hline$r / r$ & 9 & بيكار & \\
\hline $1 \cdots$ & ২А. & \multicolumn{2}{|c|}{ جمع } \\
\hline$r Y / l$ & 71 & 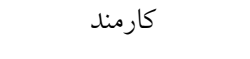 & \multirow{4}{*}{ وضعيت اشتغال مادر } \\
\hline $1 / 2$ & $\varepsilon$ & مشغول به تحصيل & \\
\hline$V T / \Lambda$ & $r \cdot 1$ & خانهدار & \\
\hline$r / 7$ & $1 \varepsilon$ & ساير & \\
\hline $1 \cdots$ & rA. & \multicolumn{2}{|c|}{ جمع } \\
\hline$\varepsilon\rceil / V$ & 99 & مهد كودى & \\
\hline
\end{tabular}




\begin{tabular}{|c|c|c|c|}
\hline $0 / 9$ & $\varepsilon \varepsilon$ & با يرستار در منزل & \\
\hline $1 \varepsilon / \wedge$ & 07 & با يدر در منزل & وضعيت نخهارى كودى \\
\hline$r Y / \tau$ & $\wedge 1$ & ساير & \\
\hline $1 \cdots$ & $r \wedge \cdot$ & \multicolumn{2}{|c|}{ جمع } \\
\hline $0 \Lambda / \Gamma$ & $17 r$ & دختر & جنسيت كودى \\
\hline$\varepsilon 1 / V$ & 111 & 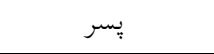 & \\
\hline $1 \cdots$ & $r \wedge \cdot$ & \multicolumn{2}{|c|}{ جمع } \\
\hline$\cdot / \wedge$ & $r / v$ & \multicolumn{2}{|c|}{ بعد خانوار } \\
\hline$\cdot / \Lambda$ & $1 / V$ & \multicolumn{2}{|c|}{ ت تعداد فرزندان } \\
\hline$\cdot / r$ & $1 / 1$ & \multicolumn{2}{|c|}{ تعداد كودكان نويا } \\
\hline$\cdot / \Lambda$ & $1 / 0$ & \multicolumn{2}{|c|}{ رتبه تولد كودى نويٍا } \\
\hline $19 / 1$ & $M T / Y$ & \multicolumn{2}{|c|}{ سن مادر } \\
\hline$r N / 7$ & $r V / V$ & \multicolumn{2}{|c|}{ سن يدر } \\
\hline$\cdot / 9$ & $r / \cdot V$ & \multicolumn{2}{|c|}{ سن كودى نويا } \\
\hline
\end{tabular}

جدول شماره r، اطلاعات مربوط به سابقه آسيب اين كودكان را نشان مىدهد.
در بين كل افراد مورد بررسى، 10 مورد (7 درصد) از كودكان نويا دجار سانحه منجر به آسيب شده بودند.

جدول شماره ؟: اطلاعات مربوط به سابقه آسيب كودكان نويا

\begin{tabular}{|c|c|c|c|}
\hline درصد & فراوانى & رده متغير & سوال \\
\hline$r \tau / 7$ & $\varepsilon$ & بلى & 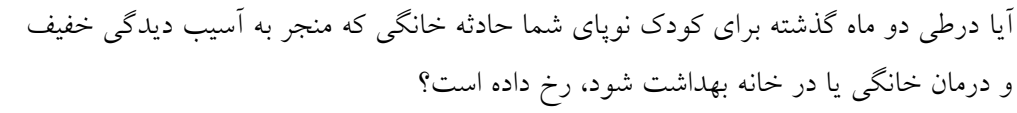 \\
\hline $1 \pi / r$ & $r$ & بلى & و آيا در طى دو ماه كذشته براى كودى نو اكز درمانى شده باشد، رخ داده است؟ حادثه خانحى كه منجر به آسيب ديدكى متوسط \\
\hline $7 . / 1$ & 9 & بلى & و ارجاع در طى دو ماه كذشته براى كودى نوياى شما حادثه خانگى كه منجر به آسيب ديدكى شديد \\
\hline $1 \varepsilon / \Gamma$ & r & 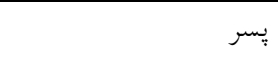 & جنسيت كودى آسيب ديده \\
\hline $10 / \mathrm{V}$ & ir & دختر & \\
\hline $0 \Lambda / V$ & Ir & 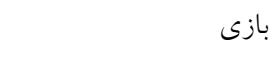 & نوع فعاليت كودى هنگحام آسيب \\
\hline $1 \varepsilon / \mu$ & r & خوردن/ آشاميدن & \\
\hline $77 / 7$ & 1. & آشيزخانه & \\
\hline $1 \pi / r$ & r & حياط & مكان آسيب \\
\hline $1 \pi / r$ & r & حمام & \\
\hline $7 / 7$ & 1 & 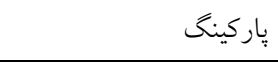 & \\
\hline$V / / \varepsilon$ & 11 & انجام امور خارج از منزل & فعاليت مادر در هنخام آسيب ديدگى كودى \\
\hline$r \Lambda / T$ & $\varepsilon$ & انجام امور منزل & \\
\hline$r \varepsilon / q$ & $\checkmark$ & سوختكى & \\
\hline$r \Lambda / T$ & $\varepsilon$ & مسموميت & نوع آسيب \\
\hline $1 \varepsilon / \Gamma$ & r & خفكى & \\
\hline $1 \varepsilon / \mu$ & r & غرق شدگى & \\
\hline$V / / \varepsilon$ & 11 & سوختكى & \\
\hline
\end{tabular}




\begin{tabular}{|c|c|c|c|}
\hline $1 \varepsilon / \Gamma$ & r & كشيدگى & ״ِحونگى و ماهيت آسيب \\
\hline $1 \varepsilon / r$ & r & 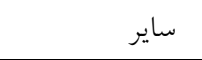 & \\
\hline$r \Lambda / 7$ & $\varepsilon$ & 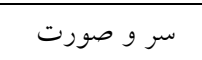 & \\
\hline $1 \varepsilon / r$ & r & دست و پا & عضو يا اندام آسيب ديده در اثر حادثه \\
\hline $0 V / 1$ & 9 & 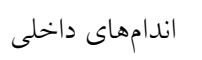 & \\
\hline$r \Lambda / 7$ & $\varepsilon$ & بهبودى & ييامد آسيب ديدكى كودى \\
\hline$V \backslash / \varepsilon$ & 11 & 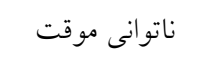 & \\
\hline$V Y / \varepsilon$ & 11 & 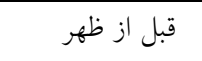 & زمان وقوع آسيب \\
\hline$r \Lambda / T$ & $\varepsilon$ & بعد از ظهر & \\
\hline $1 \ldots$ & 10 & 1/1/0 سالخى & سن كودى در زمان حادثه \\
\hline
\end{tabular}

شده است. به طورى كه با افزايش سن كودى، سطح

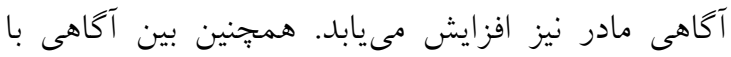

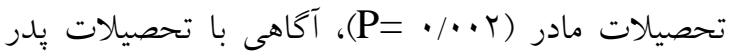

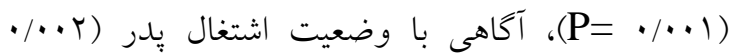

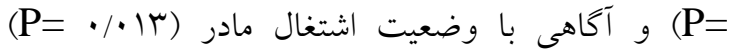
ارتباط مثبت و معنىدارى وجود دارد. بين نخرش مادر

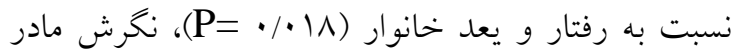

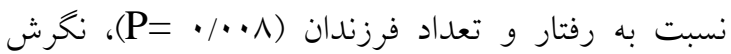

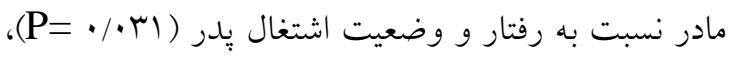

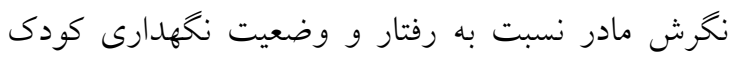

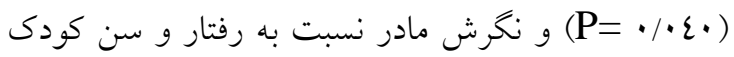

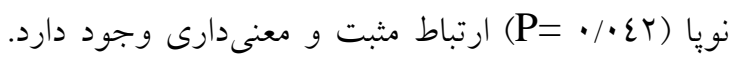

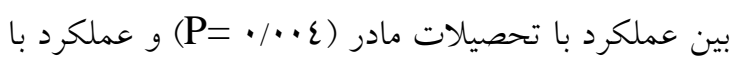

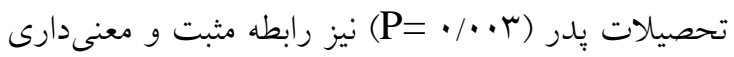
مشاهده شد. جدول شماره ع معنى دارى يافته مذكور را در سطح معنى دارى (0/0 p ) نشان مى دهد.
طبق جدول شماره "، با توجه به معيار دسته بندى جارى،

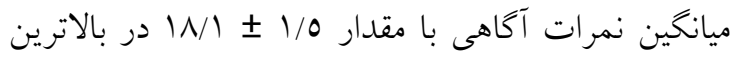
محدوده امتياز كسب شده توسط مادران (خوب)، ميانخين

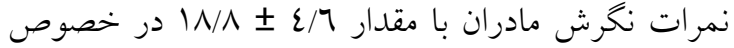
اتخاذ رفتارهاى ييشخيرانه در حيطه ضعيف و ميانكين

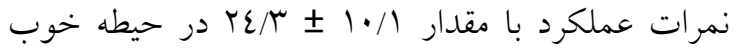

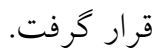

جدول شماره سّ: ميانكين، انحراف معيار و محدوده امتياز مادران در خصوص آتاهى، نكَرش و عملكرد

\begin{tabular}{|c|c|c|}
\hline محدوده امتياز & ميانكين و انحراف معيار & سازه هاى مدل \\
\hline$\cdot-Y \varepsilon$ & $1 M / 1 \pm 1 / 0$ & آكَاهى \\
\hline $17-7 \varepsilon$ & $1 N / \Lambda \pm \varepsilon / 7$ & نغرش \\
\hline rrs. & $r \Sigma / 1 \cdot \pm r / 1$ & عملكرد \\
\hline
\end{tabular}

همانطور كه در جدول شماره ع مشاهده مىشود، بين سطح آكَاهى مادر و سن كودى نويا ارتباط مثبتى مشاهده 


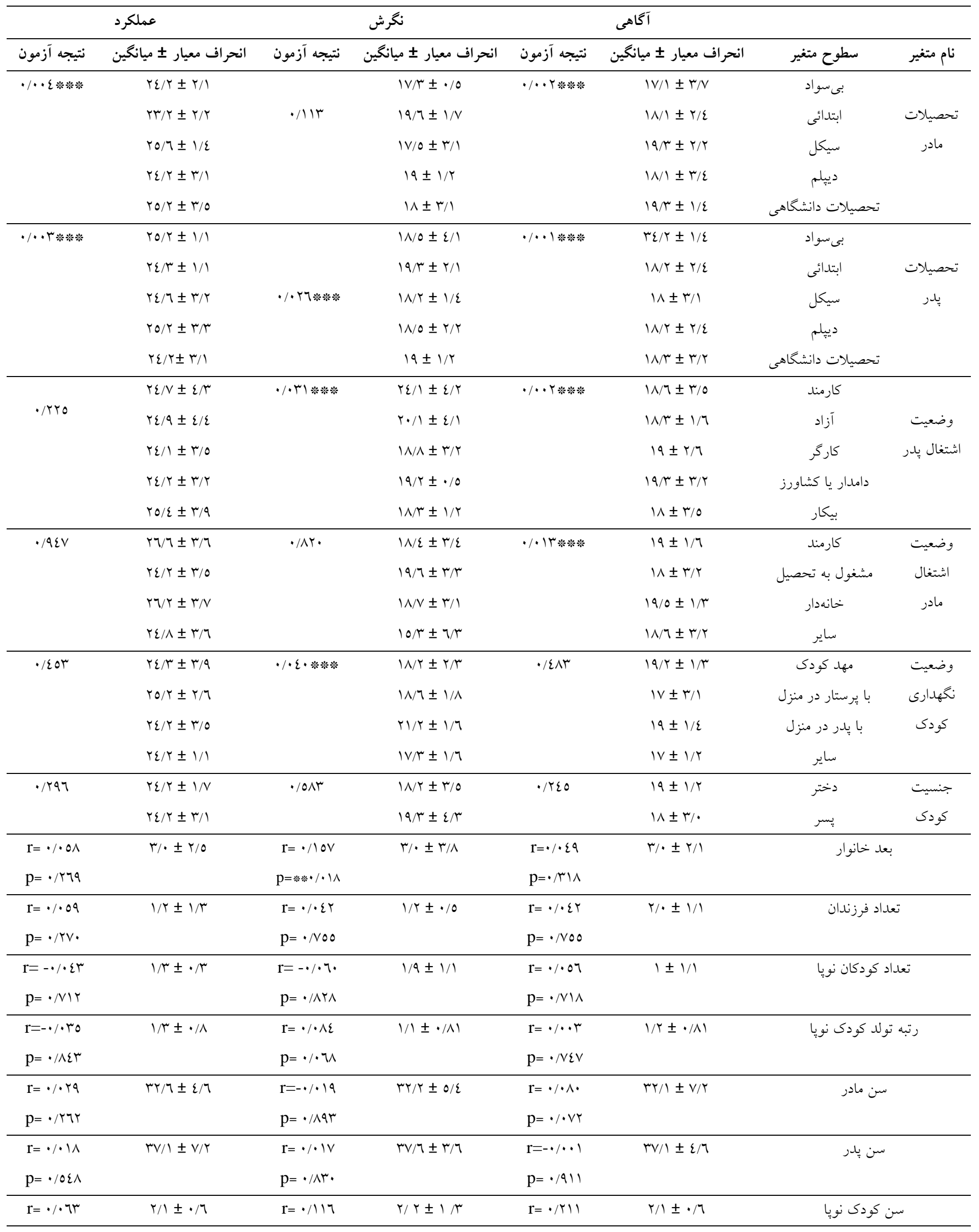


در خصوص عملكرد مادران، ميانخين نمرات خوب بود كه اين يافته مىتواند به دليل تحصيلات بالاى مادران

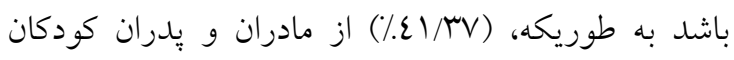

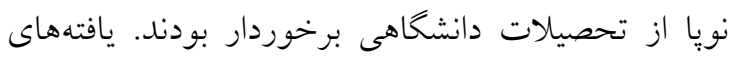

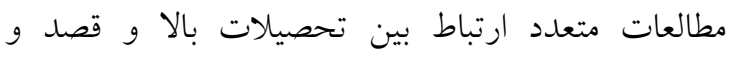

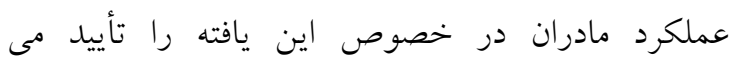

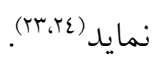
در خصوص عوامل جمعيت شناختى مؤثر بر آكاهى، نكرش و عملكرد مى توان كفت كه بين سن كودى نويا و سطح آكاهى مادر ارتباط مثبتى مشاهده شده است. به تهن طورى كه با افزايش سن كودى، سطح آكَاهى مادر نيز افزايش مى يابد. همجنين بين بعد خانوار، تعداد فرزندان و

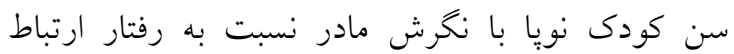
مثبت و معنىدارى وجود دارد. همجِنين بين تحصيلات

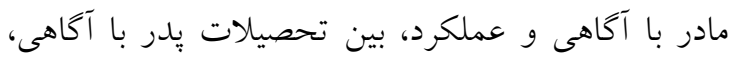
نخرش و عملكرد، بين وضعيت اشتغال بدر با آكاهى و نخرش، بين وضعيت اشتغال مادر با آكاهى و بين وضعيت نخهارى كودى با نخرش رابطه مثبت و معنىدارى مشاهلده شد. به نظر مىرسد ارتباطات يافت شده موجه مىباشند به اين صورت كه هر جهه تعداد فرزندان بيشتر بوده نخرش مادر نسبت به بيشخيرى از حوادث خانكى به دليل داشتن تجربه بيشتر بهتر مىشود، همجنين مىتوان كفت كه با بالا رفتن سن كودى آكاهى و تجربه مادر بالاتر رفته و به دنبال منافع درى شده در خصوص محافظت از كودى نخرش مادر بهتر شده، در اين راستا مىتوان به مطالعه اثنى عشرى و همكاران اشاره كرد كه در مطالعهاى تحت عنوان بررسى تأثير برنامه آموزشى بر اساس مدل بر رفتارهاى بيشخيرانه مادران از حوادث Basnef خانكى كودكان r-0 ساله شهر رى، به اين نتيجه رسيدند

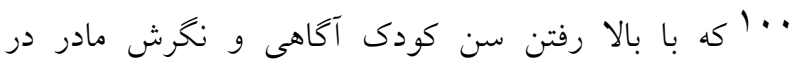

\section{بحث و نتيجه كيرى}

در مطالعه حاضر به طور ميانخين ·9 درصد مادران از سطح آكاهى متوسطى برخوردار بودند؛ اين در حالى

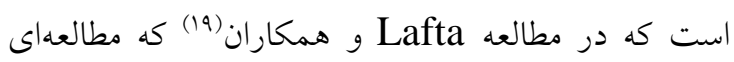
تحت عنوان بررسى سطح آكاهى مادران از بيشخيرى از حوادث خانكى در بغداد انجام دادند، ب/ 9 درصد از مادران آكاهى خوب و •9 درصد از آنها آكاهى ضعيفى داشتند. همجنين در مطالعه حاتم آبادى و همكاران(ع) نيز كه تحت عنوان ارزيابى عوامل مرتبط با اتخاذ رفتارهاى يشيشيرانه از حوادث غير عمدى خانكى در كودكان شهر تهران انجام شد، · V درصد از نمونههاى مطالعه سطح آكاهى بِايئنى داشتند. در مطالعه حاضر مادران در خصوص سازههاى نخرش ميانگين نمرات يائينى به دست آوردند كه اين به معناى ارزيابى منفى مادران از رفتارهاى بيشخيرانه از حوادث خانكى كودكان نوبِ مىباشد بنابراين انجام مداخلاتى در خصوص ارتقاء نخرش مادران در اين زمينه توسط محقق احساس مىشود. در راستاى يافته حاضر مىتوان به مطالعات محمدى زيدى (10)، معينى (.r) اميدى فرد(I) و جلمبادى(Tr) اشاره كرد كه در يزّوهش هاى ياد شده، نمونهاى يزوهش در حيطه نخرش در خصوص اتخاذ رفتارهاى يُشگيرى كننده از حوادث خانگى كودكان نمرات يُائينى را كسب كردند. همجنين در مطالعه مكرمى و همكاران(Tr) نيز كه تحت عنوان تأثير آموزش مبتنى بر تئورى رفتار برنامه ريزى شده بر رفتارهاى بيشخيرى كننده از وازينيت در سفيران سالامت

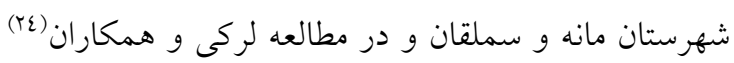
نيز كه در خصوص تعيين اثر اجراى برنامه آموزشى مبتنى بر تئورى رفتار برنامه ريزى شده بر قصد انجام رفتارهاى

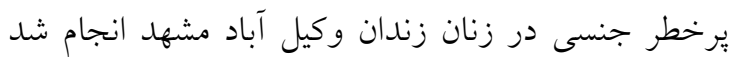
نتايج مطالعه نشان داد كه ميانخين نمرات نكرش نمونه هاى مطالعه يايين مىباشد. 
جون در مطالعه مذكور نيز بيشتر مادران در حين وقوع

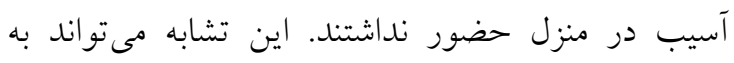

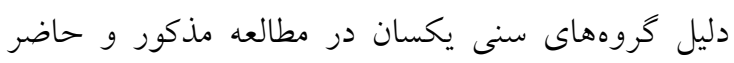
باشد. در خصوص نوع حادثه مىتوان كفت كه به ترتيب

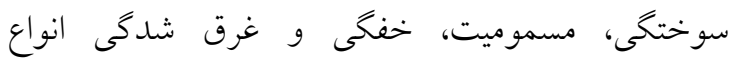
حوادثى بودند كه براى كودكان با سابقه آسيب رنّي

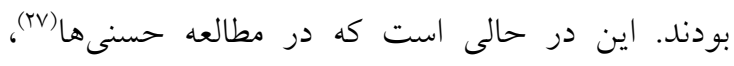

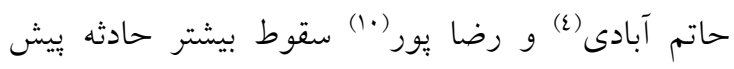

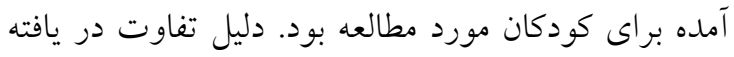

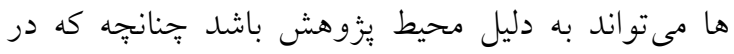
مطالعه رضايور و همكاران كودكان ساكن در روستا مورد بررسى قرار گرفته بودند كه اين مىتواند بر ايجاد يافته هاى متفاوت تأثير كذار باشد. تمامى موارد گزارش شده در گروه سنى يك تا يكى و نيم

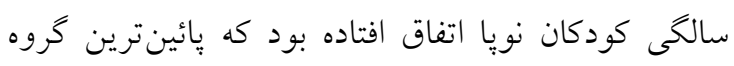
سنى در مرحله نويايى است. اين نتايج نشان مىدهد كه با باليا بالا رفتن سن كودى، تجربه مادر بالا رفته و قصد مادر

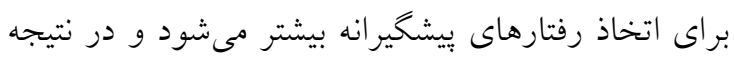

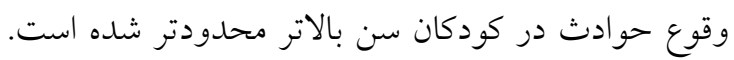
همجنين در توجيه اين مورد مىتوان كفت كه با بالا رفتن

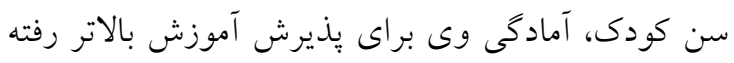

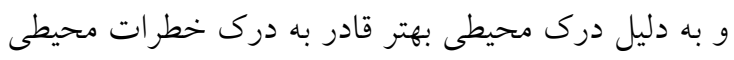

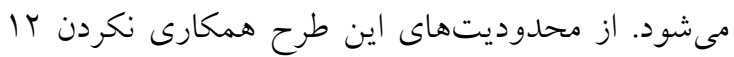
نفر از شركت كنندكان براى تكميل يرسشنامهها بود كه

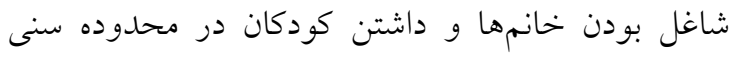
يكى تا سه سال در اين موضوع بى تأثير نبود، در رابطه با دهاب

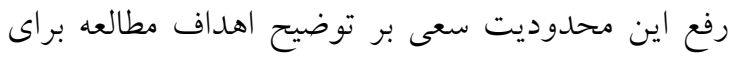
شركت كنندكان (به منظور جلب رضايت و همكارى بيشتر) و همر اهان (به منظور نخههارى كودى حين تكميل ير سشنامه توسط مادر) شد.

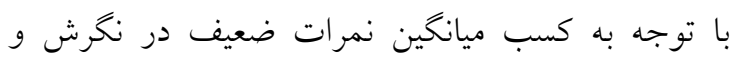

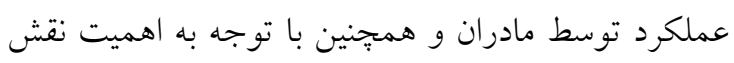

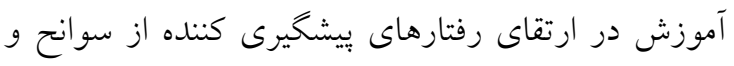

خصوص اتخاذ رفتارهاى بيشخيرانه از حوادث خانكى

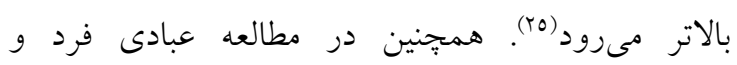

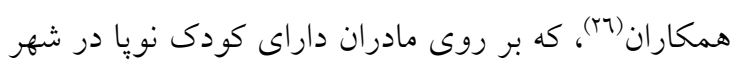
تهران انجام شد، به اين نتيجه رسيدند كه هرجهه بعد ندان

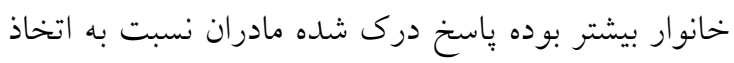

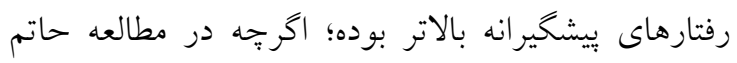

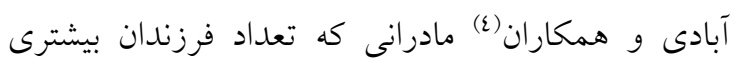
داشته عملكرد ضعيفى در اتخاذ رفتارهاى بيشخيرانه داشتند. در خصوص تفاوت يافتها مىتوان به شاغل بودن بيشتر نمونههاى مطالعه مذكور اشاره كرد كه همراه با تعلداد فرزندان بالا موانعى براى عملكرد در اين زمينه

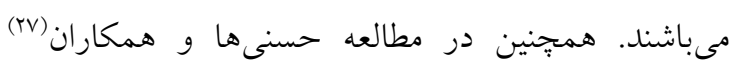

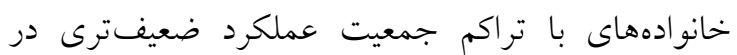
خصوص عملكرد بيشخيرانه داشتند. به نظر مىرسد آموزش در خانوادههاى با تعداد فرزند بيشتر، نسبت به بهرداله كروههاى ديخر، ضرورت بيشترى دارد.

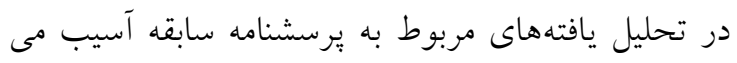

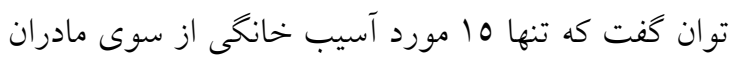

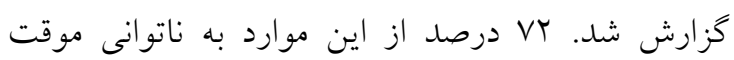

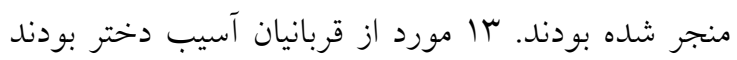

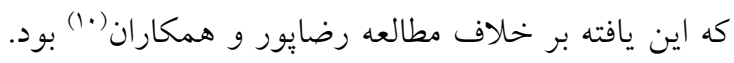

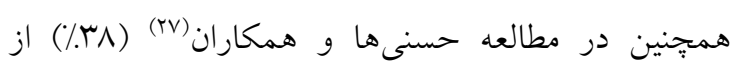

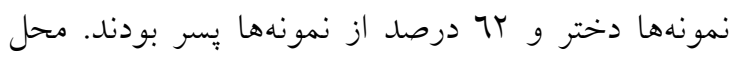

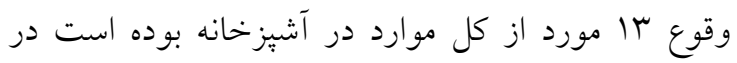
حالى كه در مطالعه حاتم آبادى و همكاران( (ع) بيشتر

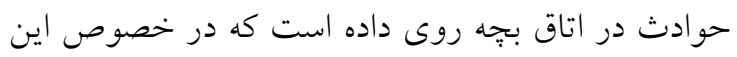

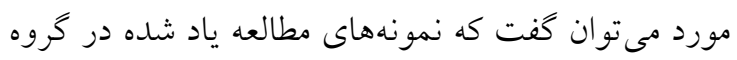

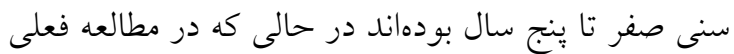
بيشتر كودكان نويا اتاق جداكانه نداشته و وابسته به مادر لئر در منزل بودند. حدود •V درصد از حوادث در صورتى روى دادهاند كه مادر در حال انجام امور خارج از منزل

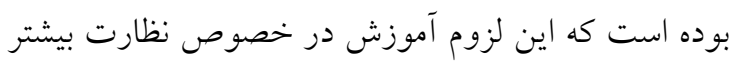

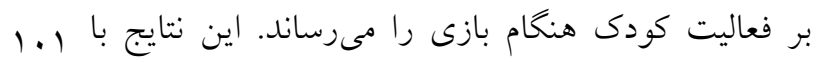

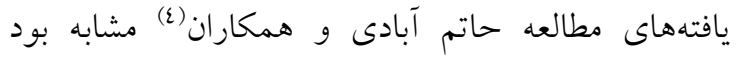




$$
\begin{aligned}
& \text { حوادث، ضرورت آموزش در ابعاد وسيعتر به منظور تعارض منافع: نويسندكان اين مقاله هيجگونه تعارض }
\end{aligned}
$$

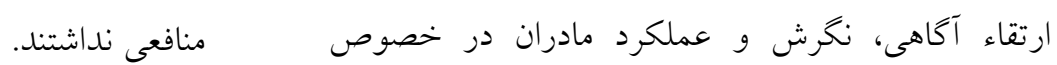

$$
\begin{aligned}
& \text { بيشخيرى از سوانح و حوادث كودكان احساس مى مَردد. } \\
& \text { تقدير و تشكر }
\end{aligned}
$$

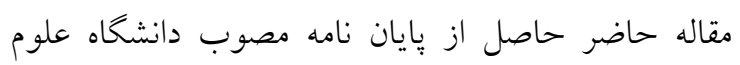

$$
\begin{aligned}
& \text { يز شكى همدان با شماره }
\end{aligned}
$$

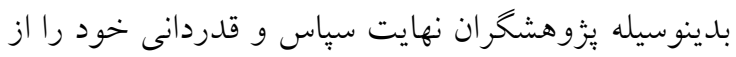

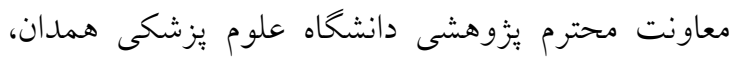

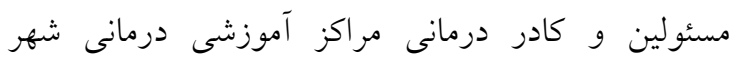

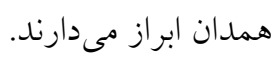

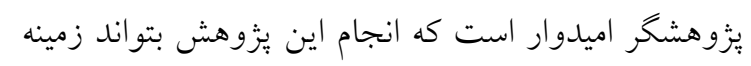

$$
\begin{aligned}
& \text { اى براى يزوهش هاى بعدى در حيطه حوادث كودكان نويا }
\end{aligned}
$$

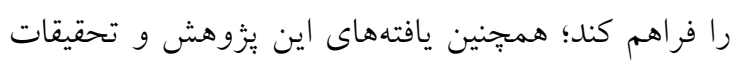

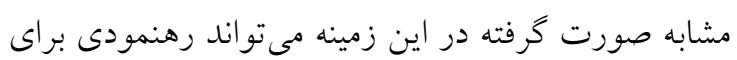

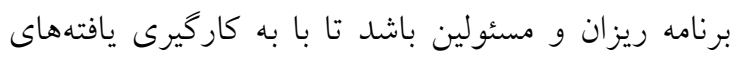

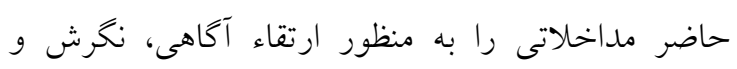

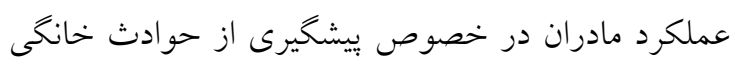

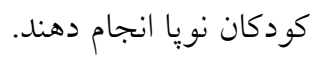

\section{References}

1. Zarei E, Dormohammadi A. Accidents analysis in a disaster and emergency medical management center. Safety promotion and injury prevention (Tehran). 2015;3(3):191-8. [Persian]

2. Gholami AH, Soltanian AR, Khalili A. The Survey of Professional Ethics Observance from Nurses' Perspective and Its Related Factors in Hamadan Medical Education Centers. Journal of Health and Care. 2020;22(1):75-83. [Persian]

3. Langiano E, Ferrara M, Lanni L, De Vito E. The childhood home accidents: risk perception and behavior. La Clinica Terapeutica. 2016;167(3):e49-54.

4. Hatam Abadi H, Mahfouzpour S, Khazaei A, Forouzanfar Mm, Yousefian Sh, Younesian S. Evaluation of factors related to the adoption of preventive behaviors from unintentional home accidents in children. Safety Improvement Magazine. 2013;1(3):140-9. [Persian]

5. Vakili M, Momeni Z, Mohammadi M, Koohgardi M. Epidemiological study of accidents in children under 6 years of Azadshahr Yazd in 2011. Pajouhan Scientific Journal. 2016;14(3):4957. [Persian]

6. Amini R, Kalvandi N, Khodaveisi M, Tapak L. Investigation of the Effect of Education Based on the Theory of Planned Behavior on the Mothers' Preventive Practices Regarding Toddler Home Injuries. Home Health Care Management \& Practice. 2021:10848223211000048.

7. Kliegman RM, Stanton BM, Geme JS, Schor NF. Nelson Textbook of Pediatrics E-Book: 2Volume Set. Elsevier Health Sciences; 2019 Apr 1.

8. Fathi M, Shamsi M, Khorsandi M. Effect of theory-based education on the promotion of preventive behaviors of accidents and injuries among mothers with under-5-years-old children. Iranian Journal of Health Education and Health Promotion. 2016;4(3):184-93. [Persian]

9. Bayram T, Ilgin C, Kulbay H, Tozakoglu B, Karaduman I, Colak BC, Save D. The factors associated with mothers' preventive measures against home accidents: a descriptive study from Istanbul, Turkey. Clin Experim Health Sci. 2019;9(2):151-6.

10. Rezapour F. Investigating Factors Related To Mothers' Beliefs And Practice In Preventing The Damage Caused By Accidents Under The Five Years Children Using Health Belief Model In Hamadan. Received From Thesis Of The Hamadan University Of Medical Sciences, Faculty Of Health. 2011. [Persian]

11. Mobasheri F, Azizi H, Rastbaf F. The epidemiological pattern of injuries among children under 15 years of age in Fasa in 2013. Journal of Fasa University of Medical Sciences. 2016;6(1):69-78. [Persian]

12. Khazaei Z, Khazaei S, Valizadeh R, Mazharmanesh S, Mirmoeini R, Mamdohi S, Pordanjani SR, Nili S, Ayubi E, Mansori K, Goodarzi E. The epidemiology of injuries and accidents in children under one year of age, during (2009-2016) in. Hamadan Province, Iran. International journal of pediatrics. 2016;4(7):2213-20. 
13. Tajedini F, Ehdaievand F, Farsar AR. Epidemiological features of children mortality in the area covered by Shahid Beheshti university of medical sciences in 2012. Journal of Clinical Nursing and Midwifery. 2014;3(1):62-71. [Persian]

14. Devi MC, Kumar A. A Descriptive study to assess the Knowledge regarding prevention of Home Accidents Among Mothers of Under five Children in Selected Areas of Guru gram, Haryana. Int J Pediat Nurs. 2018;4(1):1-8.

15. Fakhri A, Morshedi H, Zeidi IM. Effect of an educational intervention based on the theory of planned behavior on the use of hearing protection devices. Scientific Journal of Kurdistan University of Medical Sciences. 2017;22(2). [Persian]

16. Ranaei V. Investigating The Effect Of Education Using The Programmed Behavior Theory On The Behavior Of Hamedan Boy Boy Coping Students In The Prevention Of Traumatic Injuries. Received From Thesis Of The Hamadan University Of Medical Sciences, Faculty Of Health. 2016. [Persian]

17. Tajedini F, Delbarpoor ahmadi S, Ehdaievand F, Moghimi dehkordi B, Torkaman nejad S, Farsar A. Epidemiological features of children mortality in the area covered by Shahid Beheshti university of medical sciences in 2012. Journal of Clinical Nursing and Midwifery. 2014;3(1):6271. [Persian]

18. Meimanat Abadi S, Ghofranipour F, Yousefi F, Moradpour F. The Effect Of Educational Interventions Based On Honest Belief Model On The Causes Of Accidents In Subordinate Children Addressed To Health Care Centers In Ghorveh Township. Hakim Seyyed Esmaeel Jorjani. 2013;4(1):2-13. [Persian]

19. Lafta RK, Al-Shatari SA, Abass S. Mothers' knowledge of domestic accident prevention involving children in Baghdad City. Qatar Med J. 2014;2013(2):17.

20. Moeini B, Hazavehei SM, Bashirian S, Soltanian A, Mousali AA, Kafami V. Effect of educational program to encourage safe sexual behaviors among addicted men refered to substance abuse treatment centers in Hamadan, Western Iran: applying the theory of planned behavior. $J$ Educ Community Health. 2014;1(1):1-10. [Persian]

21. Omidi Fard Z, Hekmat KH, Marashi T, Bagheri R. The Effect Of Theory-Based Training On Planned Physical Activity On Women Of Reproductive Age. Afakak Scientific Journal. 2011;7(22). [Persian]

22. Jalambadani Z, Shojaei Zadeh D, Hoseini M, Sadeghi R. The effect of education for iron consumption based on the theory of planned behavior in pregnant women in Mashhad. Journal of Clinical Nursing and Midwifery. 2015;4(2):59-68. [Persian]

23. Mokarrami E, Jalili Z, Tavakoli Ghouchani H. The Effect of Education Based on the Theory of Planned Behavior on Preventive Behaviors of Vaginitis in Health Ambassadors. Iranian Journal of Health Education and Health Promotion. 2019;7(2):211-9. [Persian]

24. Larki M, Taffazoli M, Latifnejad-Roudsari R, Shakeri MT, Babaee A. The Effect of a Training Program Based on the Theory of Planned Behaviour (TPB) on Sexual High-Risk Behavioural Intentions in Female Prisonors, Vakil Abad Prison, Mashhad, Iran, 2013. Journal of Kerman University of Medical Sciences. 2016;23(4):497-514. [Persian]

25. Asna Ashari M. The Study Of The Effect Of Behvarz's Educational Program On The Basis Of The Basnef Model On The Preventive Behaviors Of Mothers From 2-5 Years Old Household Incidents In Rural Areas Of Ray City. Received From Thesis Of The Hamadan University Of Medical Sciences, Faculty Of Health. 2015. [Persian]

26. Ebadi Fardazar F, Hashemi SS, Solhi MS. The effect of educational intervention based on protection motivation theory on mothers' behaviors about prevention of home accidents in children under 5 year old. Journal of health research in community. 2016;1(4):37-44. [Persian]

27. Hasaniha M. Khoda Bandeh Loo M, Skandari F, Mazloom Zadeh S. Investigation of Socioeconomic Factors In Injured Children Referred To Ayatollah Mousavi And Valiasr Hospitals In Zanjan. Journal Of Social Health. 2015;2(3):165-71. [Persian] 